\title{
The role of retreatment in the management of recurrent/ progressive brain metastases: a systematic review and evidence-based clinical practice guideline
}

\author{
Mario Ammirati $\cdot$ Charles S. Cobbs $\cdot$ Mark E. Linskey $\cdot$ Nina A. Paleologos • \\ Timothy C. Ryken - Stuart H. Burri • Anthony L. Asher $\cdot$ Jay S. Loeffler • \\ Paula D. Robinson · David W. Andrews · Laurie E. Gaspar · Douglas Kondziolka • \\ Michael McDermott $\cdot$ Minesh P. Mehta $\cdot$ Tom Mikkelsen · Jeffrey J. Olson • \\ Roy A. Patchell $\cdot$ Steven N. Kalkanis
}

Received: 7 September 2009/Accepted: 8 November 2009/Published online: 3 December 2009

(C) The Author(s) 2009. This article is published with open access at Springerlink.com

\begin{abstract}
Question

What evidence is available regarding the use of whole brain radiation therapy (WBRT), stereotactic radiosurgery (SRS), surgical resection or chemotherapy for the treatment of recurrent/progressive brain metastases?

Target population

This recommendation applies to adults with recurrent/ progressive brain metastases who have previously been treated with WBRT, surgical resection and/or radiosurgery. Recurrent/progressive brain metastases are defined as metastases that recur/progress anywhere in the brain (original and/or non-original sites) after initial therapy.

\section{Recommendation}

Level 3 Since there is insufficient evidence to make definitive treatment recommendations in patients with recurrent/
\end{abstract}

Mario Ammirati, Charles S. Cobbs contributed equally as primary authors.

\section{Ammirati}

Department of Neurosurgery, Ohio State University

Medical Center, Columbus, OH, USA

C. S. Cobbs

Department of Neurosciences, California Pacific Medical Center,

San Francisco, CA, USA

\section{E. Linskey}

Department of Neurosurgery, University of California-Irvine Medical Center, Orange, CA, USA

\section{N. A. Paleologos}

Department of Neurology, Northshore University Health

System, Evanston, IL, USA progressive brain metastases, treatment should be individualized based on a patient's functional status, extent of disease, volume/number of metastases, recurrence or progression at original versus non-original site, previous treatment and type of primary cancer, and enrollment in clinical trials is encouraged. In this context, the following can be recommended depending on a patient's specific condition: no further treatment (supportive care), reirradiation (either WBRT and/or SRS), surgical excision or, to a lesser extent, chemotherapy.

\section{Question}

If WBRT is used in the setting of recurrent/progressive brain metastases, what impact does tumor histopathology have on treatment outcomes?

No studies were identified that met the eligibility criteria for this question.

T. C. Ryken

Department of Neurosurgery, Iowa Spine and Brain Institute, Iowa City, IA, USA

\section{S. H. Burri}

Department of Radiation Oncology, Carolinas Medical Center, Charlotte, NC, USA

\section{A. L. Asher}

Department of Neurosurgery, Carolina Neurosurgery and Spine Associates, Charlotte, NC, USA

\section{J. S. Loeffler}

Department of Radiation Oncology, Massachusetts General Hospital, Boston, MA, USA 
Keywords Recurrent/progressive brain metastases . Surgical resection. Whole brain radiotherapy .

Stereotactic radiosurgery - Chemotherapy ·

Histopathology · Retreatment - Systematic review .

Practice guideline

\section{Rationale}

Untreated brain metastases have a median survival of about 4 weeks with almost all patients dying from neurological rather than systemic causes [1]. The majority of studies which have compared different modalities for the treatment of brain metastases have focused on the management of newly diagnosed patients. The role of WBRT, surgical excision, SRS and chemotherapy for patients with newly diagnosed brain metastases are addressed by other guideline papers in this series (Gaspar et al., Kalkanis et al., Linskey et al., and Mehta et al.).

For those individuals who survive long enough to experience recurrence/progression of previously treated brain metastases, no consensus on treatment exists. The overall objective of this guideline paper is to systematically review the existing data relevant to the treatment of patients who develop recurrent/progressive brain metastases after initial therapy and to provide recommendations based on this evidence.

The questions specifically addressed by this guideline paper are:

1. What evidence is available regarding the use of WBRT, SRS, surgical resection or chemotherapy for the treatment of recurrent/progressive brain metastases?

\section{P. D. Robinson}

McMaster University Evidence-Based Practice Center,

Hamilton, ON, Canada

D. W. Andrews

Department of Neurosurgery, Thomas Jefferson University, Philadelphia, PA, USA

L. E. Gaspar

Department of Radiation Oncology, University

of Colorado-Denver, Denver, CO, USA

D. Kondziolka

Department of Neurological Surgery, University of Pittsburgh

Medical Center, Pittsburgh, PA, USA

M. McDermott

Department of Neurosurgery, University of California

San Francisco, San Francisco, CA, USA

M. P. Mehta

Department of Human Oncology, University of Wisconsin

School of Public Health and Medicine,

Madison, WI, USA
2. If WBRT is used in this setting, what impact does tumor histopathology have on treatment outcomes?

\section{Methods}

Search strategy

The following electronic databases were searched from 1990 to September 2008: MEDLINE ${ }^{\circledR}$, Embase $^{\circledR}$, Cochrane Database of Systematic Reviews, Cochrane Controlled Trials Registry, Cochrane Database of Abstracts of Reviews of Effects. A broad search strategy using a combination of subheadings and text words was employed. The search strategy is documented in the methodology paper for this guideline series by Robinson et al. [2] Reference lists of included studies were also reviewed.

\section{Eligibility criteria}

(a) What evidence is available regarding the use of WBRT, SRS, surgical resection or chemotherapy for the treatment of recurrent and/or progressive brain metastases?

- Published in English with a publication date of 1990 forward.

- Patients with recurrent and/or progressive brain metastases.

- Fully-published primary studies (all study designs for primary data collection included; e.g., RCT, non-randomized trials, cohort studies, casecontrol studies or case series).

T. Mikkelsen

Department of Neurology, Henry Ford Health System, Detroit, MI, USA

\section{J. J. Olson}

Department of Neurosurgery, Emory University School of Medicine, Atlanta, GA, USA

R. A. Patchell

Department of Neurology, Barrow Neurological Institute, Phoenix, AZ, USA

S. N. Kalkanis $(\bowtie)$

Hermelin Brain Tumor Center, Department of Neurosurgery, Henry Ford Health System, 2799 West Grand Blvd, K-11, Detroit, MI 48202, USA

e-mail: kalkanis@neuro.hfh.edu; skalkan1@hfhs.org 
- Any study evaluating the use of WBRT, SRS, surgical excision, or chemotherapy alone or in combination.

- Number of study participants with recurrent and/ or progressive brain metastases $>5$ per study arm for comparative studies and $>5$ overall for noncomparative studies.

- For studies evaluating interventions exclusively in patients with recurrent and/or progressive brain metastases, baseline characteristics of study participants are provided by treatment group for comparative designs and overall for non-comparative studies. For studies with mixed populations (i.e., includes participants with conditions other than recurrent and/or progressive brain metastases), baseline characteristics are provided for the sub-group of participants with recurrent and/or progressive brain metastases, and stratified by treatment group for comparative studies.

(b) If WBRT is used, what impact does tumor histopathology have on treatment outcomes?

- Published in English with a publication date of 1990 forward.

- Patients with recurrent and/or progressive brain metastases.

- Fully-published peer-reviewed primary studies (all study designs for primary data collection included; e.g., RCT, non-randomized trials, cohort studies, case-control studies or case series).

- Any study evaluating the outcome(s) of WBRT by tumor histopathology (or primary tumor type).

- Number of study participants with recurrent and/ or progressive brain metastases $>5$ per study arm for comparative studies and $>5$ overall for noncomparative studies.

- For studies evaluating the outcome(s) of WBRT by histopathology (or primary tumor type) exclusively in patients with recurrent and/or progressive brain metastases, baseline characteristics are presented and stratified by histologic/primary tumor group. For studies with mixed populations (i.e., includes participants with conditions other than recurrent and/or progressive brain metastases), baseline characteristics are presented and stratified by histologic/primary tumor group for the sub-group of participants with recurrent and/or progressive brain metastases.

Study selection and quality assessment

Two independent reviewers evaluated citations using a priori criteria for relevance and documented decisions in standardized forms. Cases of disagreement were resolved by a third reviewer. The same methodology was used for full text screening of potentially relevant papers. Studies which met the eligibility criteria were data extracted by one reviewer and the extracted information was checked by a second reviewer. The PEDro scale $[3,4]$ was used to rate the quality of randomized trials. The quality of comparative studies using non-randomized designs was evaluated using eight items selected and modified from existing scales.

Evidence classification and recommendation levels

Both the quality of the evidence and the strength of the recommendations were graded according to the American Association of Neurological Surgeons (AANS)/Congress of Neurological Surgeons (CNS) criteria. These criteria are provided in the methodology paper accompanying this guideline series.

Guideline development process

The AANS/CNS convened a multi-disciplinary panel of clinical experts to develop a series of practice guidelines on the management of brain metastases based on a systematic review of the literature conducted in collaboration with methodologists at the McMaster University Evidencebased Practice Center.

\section{Scientific foundation}

What evidence is available regarding the use of WBRT, SRS, surgical resection or chemotherapy for the treatment of recurrent/progressive brain metastases?

In total, 30 studies met the eligibility criteria for this question (Fig. 1). Of these studies, three evaluated the use of WBRT [5-7], four addressed the role of surgical resection [8-11], 13 reported on the use of radiosurgery [12-24] and 10 evaluated chemotherapeutic agents [25-34] for the treatment of recurrent/progressive brain metastases. The details of each are outlined in Tables 1, 2, 3, 4.

No class I or II evidence was identified that specifically addressed the question of which therapies (i.e., repeated WBRT, SRS, surgery or chemotherapy) were beneficial in the setting of recurrent/progressive metastatic brain. In fact, only one of the 30 included studies compared different modalities for the treatment of recurrent/progressive brain metastases [15]. The remaining 29 papers provide noncomparative outcome data on the treatment of recurrent/ progressive brain metastases.

\section{WBRT}

Three case series addressed the question of whether re-administration of WBRT was beneficial for patients in 
Fig. 1 Flow of studies to final number of eligible studies of retreatment of recurrent brain metastases

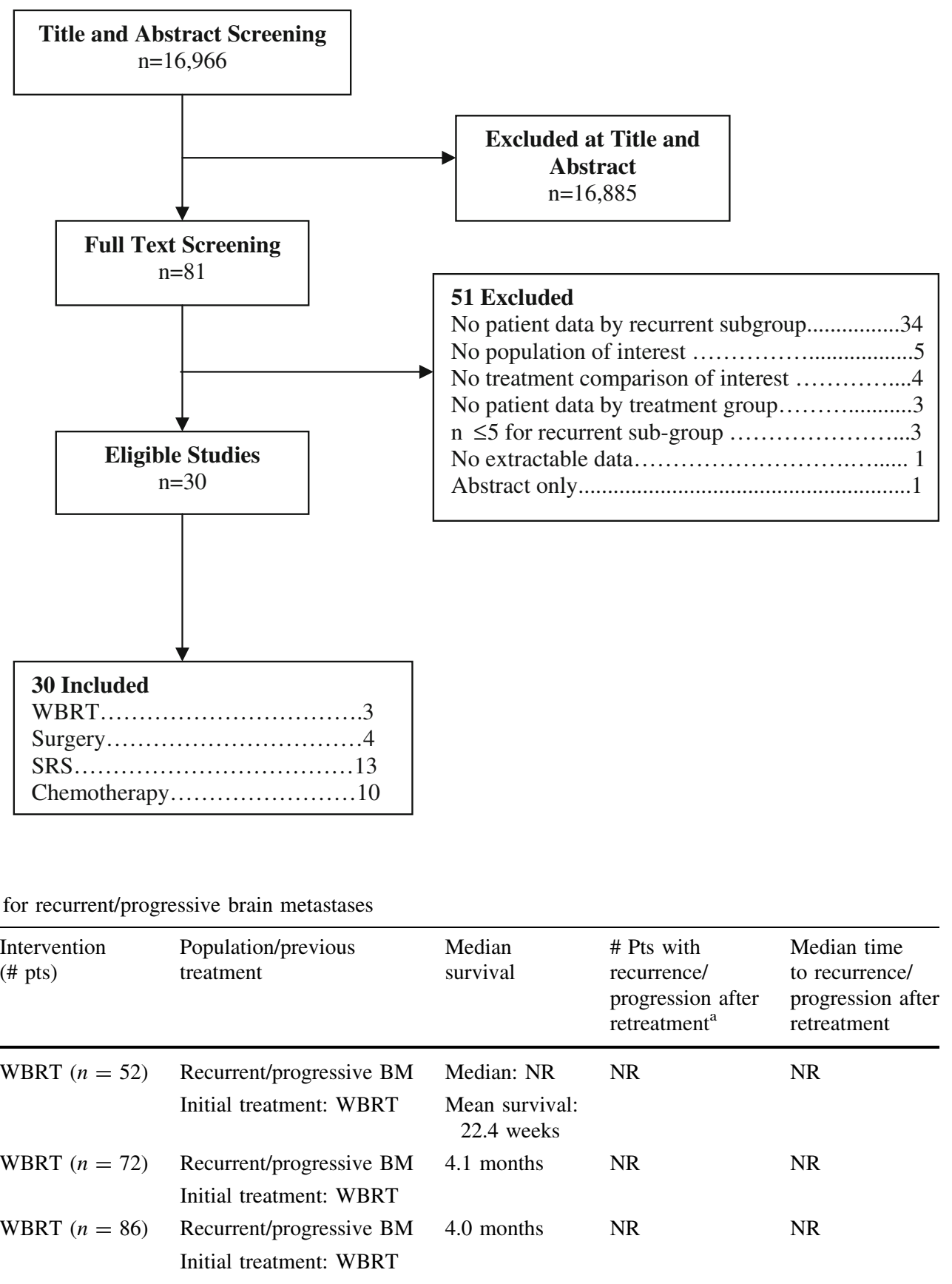

Table 1 Re-irradiation with WBRT for recurrent/progressive brain metastases

\begin{tabular}{|c|c|c|c|c|c|c|}
\hline $\begin{array}{l}\text { First author } \\
\text { (Year) }\end{array}$ & $\begin{array}{l}\text { Study design/ } \\
\text { evidence class }\end{array}$ & $\begin{array}{l}\text { Intervention } \\
\text { (\# pts) }\end{array}$ & $\begin{array}{l}\text { Population/previous } \\
\text { treatment }\end{array}$ & $\begin{array}{l}\text { Median } \\
\text { survival }\end{array}$ & $\begin{array}{l}\text { \# Pts with } \\
\text { recurrence/ } \\
\text { progression after }_{\text {retreatment }^{\mathrm{a}}}\end{array}$ & $\begin{array}{l}\text { Median time } \\
\text { to recurrence/ } \\
\text { progression after } \\
\text { retreatment }\end{array}$ \\
\hline $\begin{array}{l}\text { Cooper [5] } \\
\quad(1990)\end{array}$ & $\begin{array}{l}\text { Case series } \\
\text { Evidence class III }\end{array}$ & WBRT $(n=52)$ & $\begin{array}{l}\text { Recurrent/progressive BM } \\
\text { Initial treatment: WBRT }\end{array}$ & $\begin{array}{l}\text { Median: NR } \\
\text { Mean survival: } \\
22.4 \text { weeks }\end{array}$ & NR & NR \\
\hline $\begin{array}{l}\text { Sadikov [6] } \\
\text { (2007) }\end{array}$ & $\begin{array}{l}\text { Case series } \\
\text { Evidence class III }\end{array}$ & WBRT $(n=72)$ & $\begin{array}{l}\text { Recurrent/progressive BM } \\
\text { Initial treatment: WBRT }\end{array}$ & 4.1 months & NR & NR \\
\hline $\begin{array}{l}\text { Wong [7] } \\
\text { (1997) }\end{array}$ & $\begin{array}{l}\text { Case series } \\
\text { Evidence class III }\end{array}$ & WBRT $(n=86)$ & $\begin{array}{l}\text { Recurrent/progressive BM } \\
\text { Initial treatment: WBRT }\end{array}$ & 4.0 months & NR & NR \\
\hline
\end{tabular}

BM Brain metastases, NR Not reported, Pts Patients, WBRT Whole-brain radiation therapy

${ }^{\text {a }}$ Number of pts with recurrence/progression of brain metastases, unless otherwise specified

whom previously treated brain metastases recurred/ progressed [5-7] (Table 1). These studies are retrospective analyses of 52, 72 and 86 patients, respectively, and they offer only very limited data as to whether patients died from neurologic causes versus systemic disease progression. The average re-irradiation dose for these patients was in the range of 20-25 Gy over multiple fractions. The postre-irradiation median survival was 4 or 5 months in all of the series.
In the largest of the case series $(n=86), 70 \%$ of patients had either complete or partial resolution of neurological symptoms following re-irradiation. In the two other case series, the percentage of patients whose neurologic function improved following re-irradiation was $42 \%$ and $31 \%$, respectively $[5,6]$.

One patient experienced symptoms of dementia attributed to radiation therapy in each of the two series reporting information on longer term adverse effects $[6,7]$. 
Table 2 Surgical resection for recurrent/progressive brain metastases

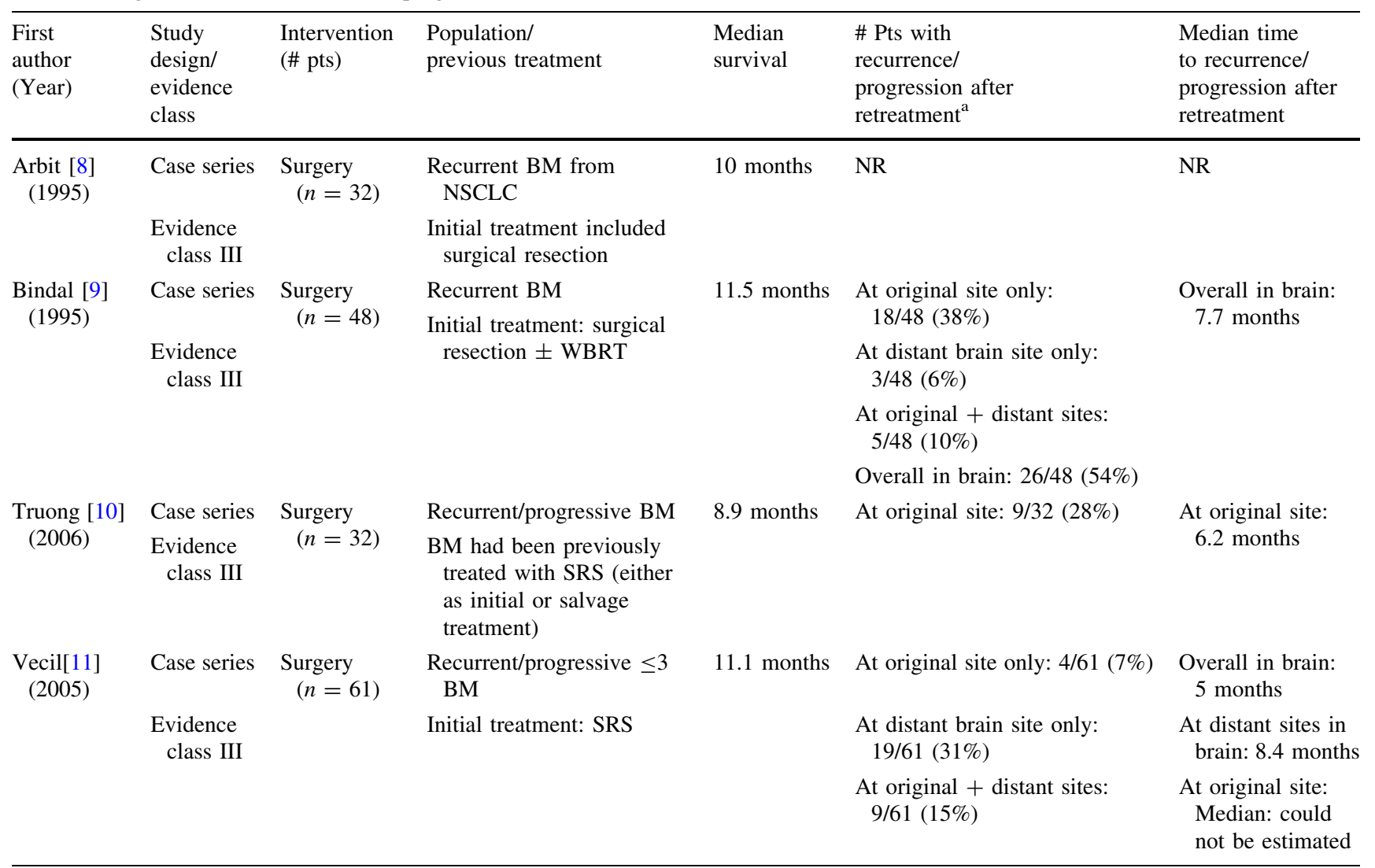

$B M$ Brain metastases, NR Not reported, NSCLC Non-small cell lung cancer, Pts Patients, SRS Stereotactic radiosurgery, WBRT Whole-brain radiation therapy

${ }^{a}$ Number of pts with recurrence/progression of brain metastases, unless otherwise specified

No studies were identified that evaluated the use of WBRT in the setting of recurrent/progressive brain metastases for patients whose initial management did not include WBRT.

\section{Surgical resection}

Four cases series addressed the use of surgical resection for recurrent/progressive brain metastases [8-11], as outlined in Table 2. Two of these retrospective studies reported outcomes for patients who underwent surgical resection for recurrent/progressive brain metastases who also had previously been treated with SRS \pm WBRT $[10,11]$. In the study by Vecil et al. 61 patients with three or fewer recurrent brain metastases underwent surgical resection for at least one index brain metastasis [11]. Treatment of non-index brain metastases varied. Major surgical complications occurred in seven patients. From the date of resection, median survival was 11.1 months and median time to any recurrence in the brain was 5 months. Cause of death was neurologic in $15 \%$ of patients and neurologic/ systemic combined in $34 \%$. The second study, conducted by Truong et al., included 32 patients who had previously been treated with SRS and who had MRI and/or clinical evidence of brain metastasis progression. To be considered for surgical resection, patients needed to have a KPS $\geq 60$ and stable or absent systemic disease. Median survival from the time of resection was 8.9 months. Seven patients experienced surgical complications. Cause of death was neurologic in $48 \%$ of patients [10].

Two case series evaluated the outcome of re-operation for recurrent brain metastases $[8,9]$. Bindal et al. reported on 48 patients who had surgical resection of a brain metastasis as part of their initial treatment and then underwent resection for recurrent disease. From the time of re-operation, median survival was 11.5 months and the median time to recurrence was 7.7 months. Of the 26 patients who developed a second recurrence, 17 underwent another surgical resection. For the 25 patients in which cause of death was known, it was neurologic in $48 \%$ and combined neurologic/systemic in $12 \%$ [9]. As part of a larger study, Arbit et al., provide retrospective data on 32 patients with non-small cell lung cancer (NSCLC) who underwent re-operation for recurrent brain metastases. From 


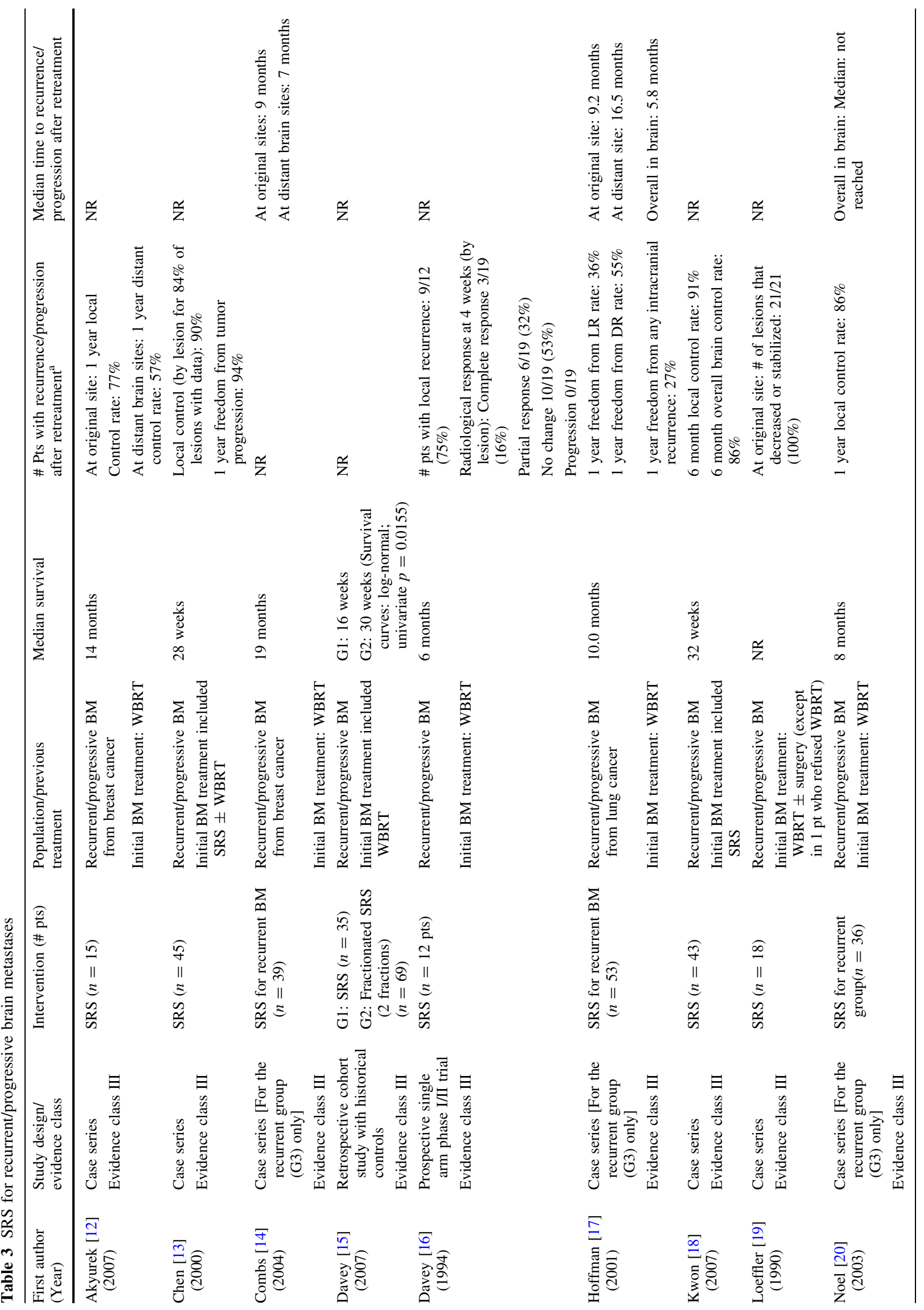




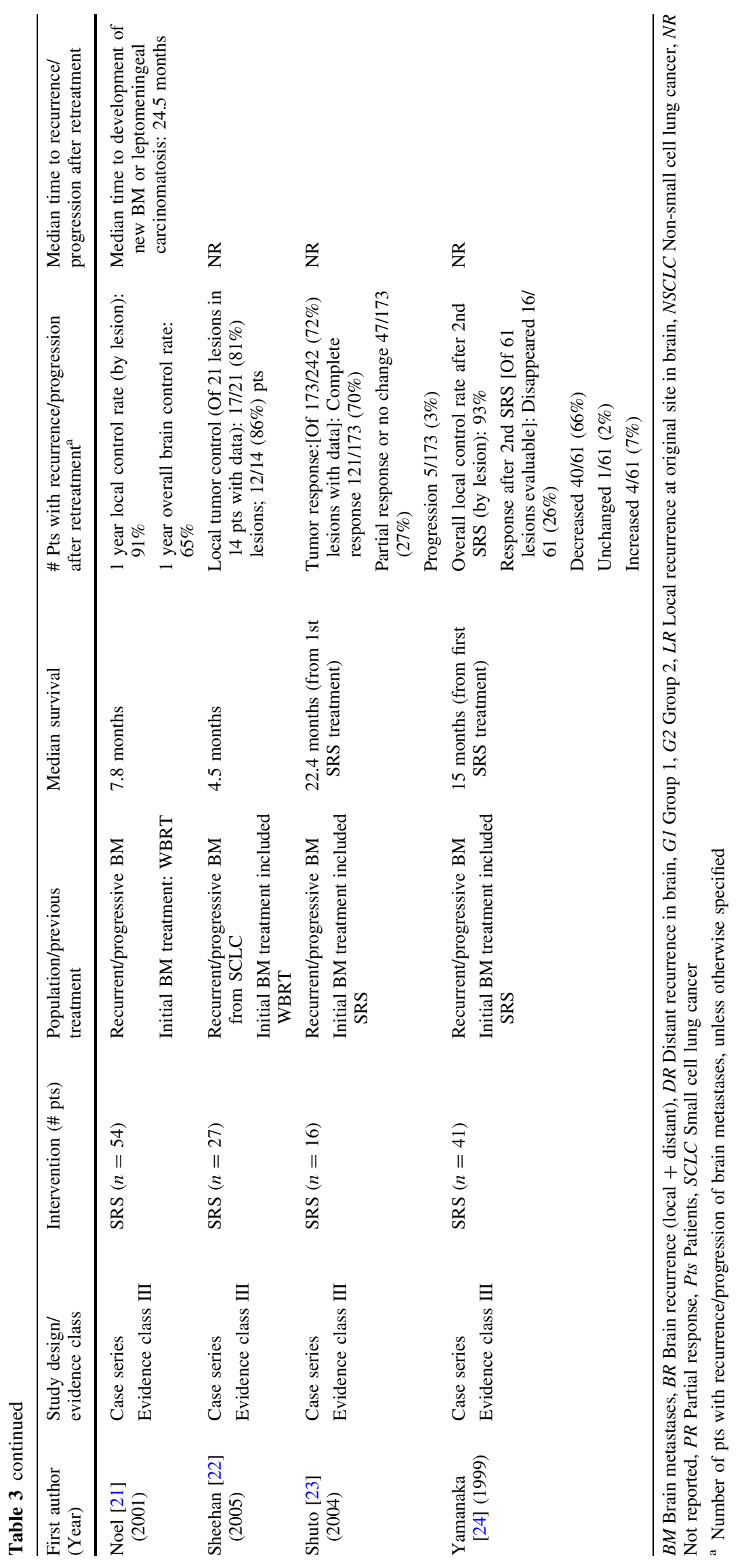


the date of re-operation, median survival was 10 months. Time to recurrence/progression was not reported [8].

\section{SRS}

Thirteen studies addressed the role of SRS for recurrent/ progressive brain metastases [12-24]. Nine studies evaluated the use of SRS for recurrent/progressive disease in patients whose initial management included WBRT [12, 14-17, 19-22]. One of these studies was prospective [16]. This single-arm phase I/II study enrolled 12 patients whose life expectancy was $\geq 3$ months and who had both clinical and radiologic evidence of brain metastases progression following treatment with WBRT. All patients were followed to recurrence at the SRS treated site or until death. In total, 20 brain metastases in the 12 patients were treated by radiosurgery. From the date of SRS treatment, median survival was 6 months. Nine patients developed evidence of progressive disease at SRS treated sites. Time to progression was not reported. Of the other eight studies that addressed the role of SRS for recurrent disease in patients whose upfront treatment included WBRT, four specifically evaluated SRS treatment for recurrent/progressive brain metastases from particular primary tumor types-breast cancer ( 2 case series $[12,14]$ ), small cell lung cancer (SCLC) (1 case series [22]) and lung cancer, predominantly NSCLC ( 1 case series [17]). See Table 3 for details.

The only comparative study that met the eligibility criteria for the systematic review evaluated single-dose SRS versus split-dose (2 dose) SRS for recurrent/progressive disease in 104 patients whose initial management included WBRT [15]. In this retrospective cohort study with historical controls, median survival was significantly longer for patients who received split-dose SRS compared to single-dose SRS (30 vs. 16 weeks; $p=0.015$ ). Time to recurrence/progression was not reported.

Four case series evaluated the use of SRS for recurrent/ progressive brain metastases in patients whose previous treatment included radiosurgery [13, 18, 23, 24], as outlined in Table 3. Only two of these case series provide survival data from the date of SRS for recurrent disease [13, 18]. In the series by Kwon et al., of 43 patients who underwent salvage SRS, median survival from the time of SRS for recurrent/progressive disease was 32 weeks and the local control rate at 6 months was $91 \%$ [18]. In the case series by Chen et al., of 45 patients, median survival from the time of SRS for recurrent brain metastases was 28 weeks [13]. The 1 year freedom from progression rate was $94 \%$.

\section{Chemotherapy}

Ten studies evaluated the role of chemotherapy in patients with recurrent/progressive metastatic brain disease [25-34].
Of these, five are prospective single arm phase II studies [25, $27,29,31,32]$ and five are case series [26, 28, 30, 33, 34]. Refer to Table 4 for details. The agents used in these studies varied from intracarotid administration of cisplatin, to temozolomide alone or with thalidomide, vinorelbine, fotemustine or cisplatin. Five of the studies investigated the role of chemotherapy specifically for patients with recurrent/ progressive brain metastases from particular primary tumor types-melanoma (3 studies) [26, 28, 31], NSCLC (1 study) [29], and SCLC (1 study) [30].

Median survival in patients with recurrent/progressive brain metastases treated with chemotherapy ranged from 3.5 to 6.6 months [25-34]. The median time to recurrence after retreatment with chemotherapy in these studies ranged from 2 to 4 months. These studies indicate that some patients with recurrent or progressive brain metastases will have an objective radiographic response and/or improvement in functional status after treatment with chemotherapy.

If WBRT is used in the setting of recurrent and/or progressive brain metastases, what impact does tumor histopathology have on treatment outcomes?

No studies were identified that met the eligibility criteria for this question.

\section{Discussion and conclusions}

No studies that provide class I or II evidence were identified which met the eligibility criteria and specifically addressed the question of which adjuvant therapies (i.e., WBRT, SRS, surgical resection or chemotherapy) are beneficial in the setting of recurrent/progressive metastatic brain tumors. Furthermore, all but one of the included studies that provide class III evidence on this topic are noncomparative. While multiple randomized clinical trials have examined the benefits for up-front combined therapies (e.g., WBRT plus SRS, WBRT plus surgery), none have been performed specifically to address the question of the benefits of further SRS, surgery or chemotherapy in cases of recurrent/progressive brain metastases. Therefore, no level 1 or level 2 recommendations can be made.

Given that none of the included studies compared the different modalities (WBRT, SRS, surgical resection or chemotherapy) for the treatment of recurrent/progressive brain metastases, the relative merits of one approach versus another are yet to be determined. Furthermore, retrospective studies of patients with recurrent/progressive brain metastases who have previously undergone WBRT, and then received subsequent re-irradiation, show conflicting results with regard to neurologic improvement and quality of life.

It is recommended that treatment of recurrent/progressive brain metastases be individualized based on functional status, extent of disease, volume/number of metastases, 


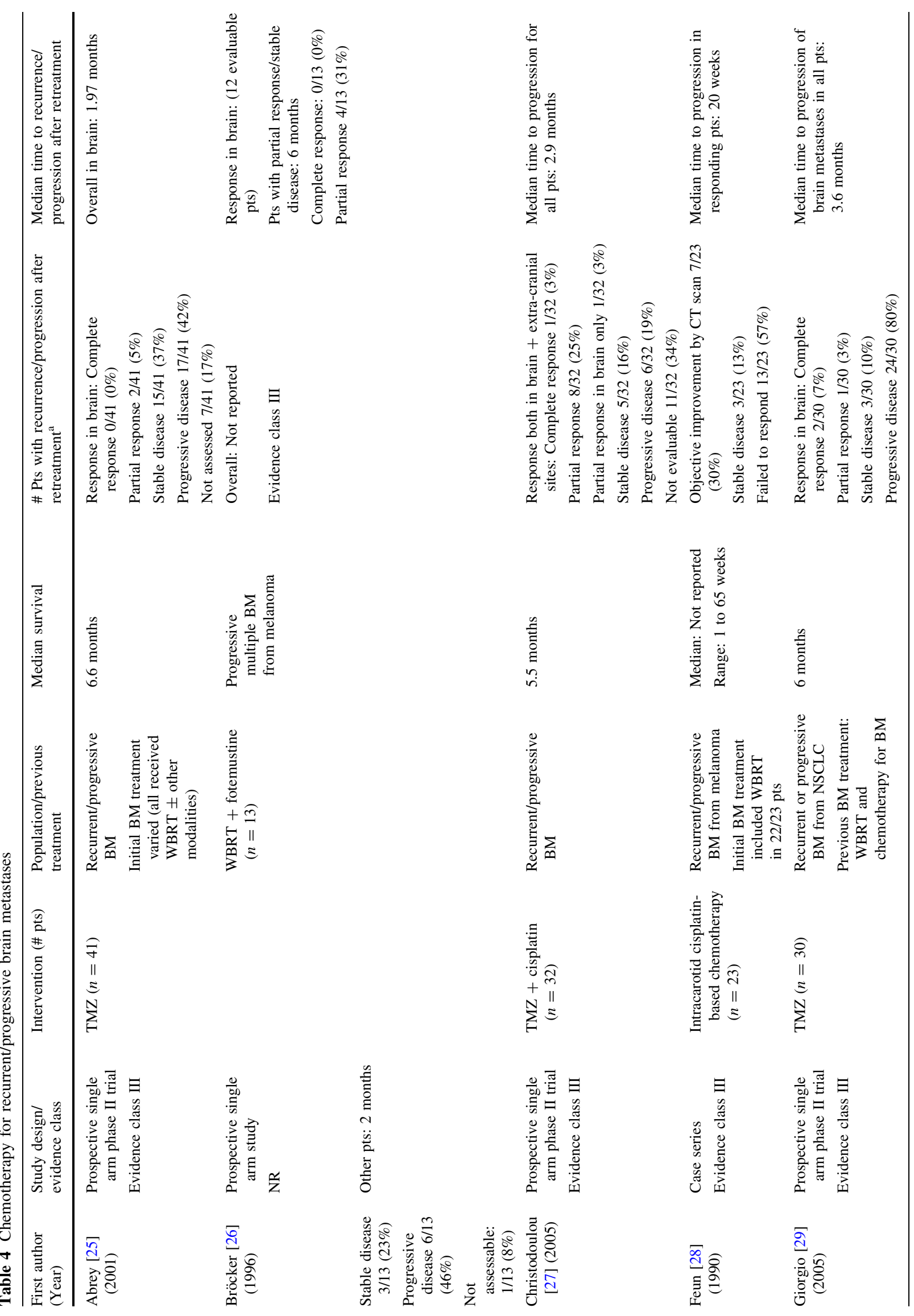




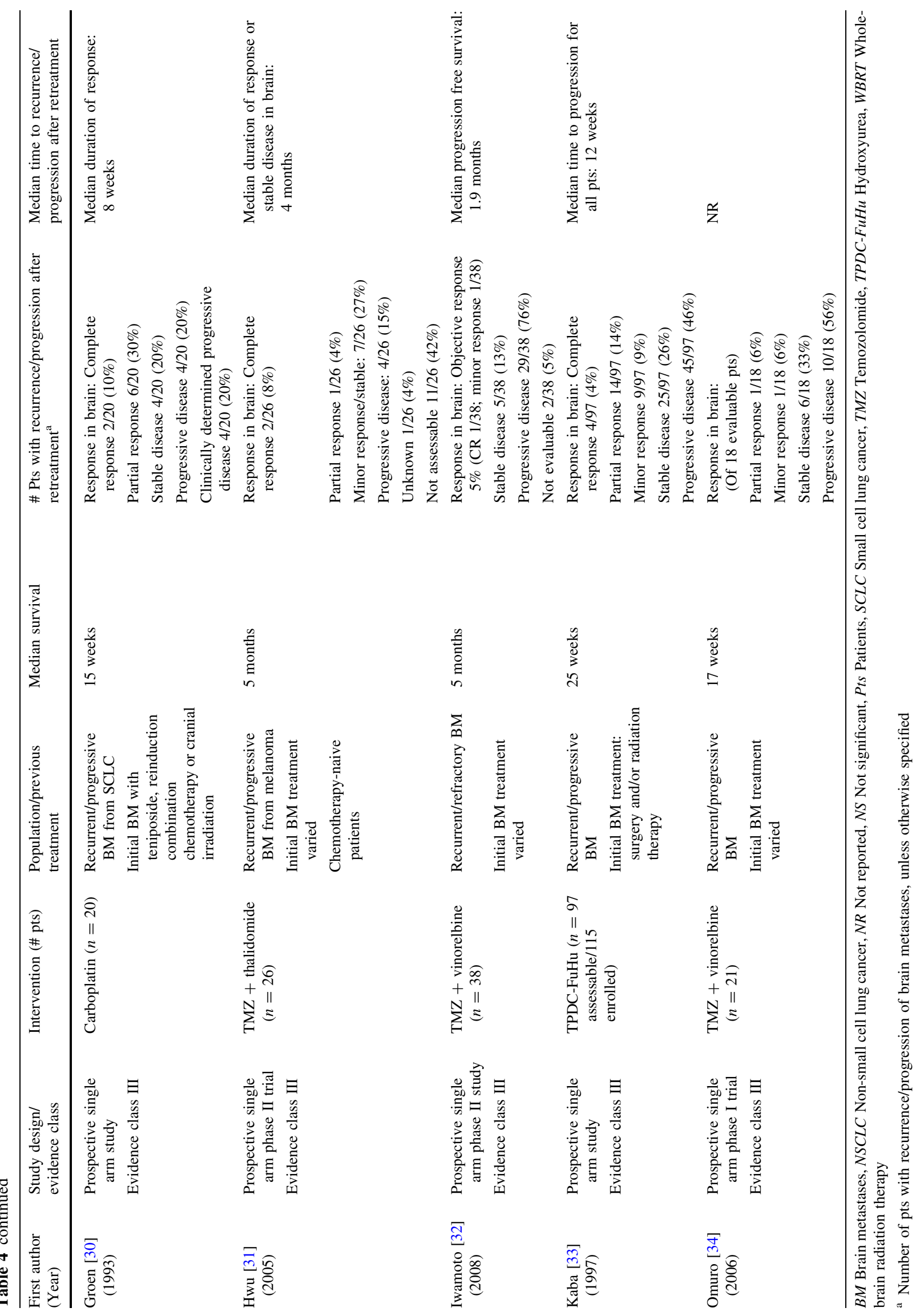


recurrence or progression at original versus non-original site, previous treatment and type of primary cancer. In this context, re-irradiation (either WBRT and/or SRS), surgical excision or, to a lesser extent, chemotherapy, can be recommended depending on a patient's specific condition and based on the judgment of the patient's treating physician.

As no studies were identified that met the eligibility criteria for the question addressing whether tumor histopathology impacts treatment outcomes when WBRT is used in the setting of recurrent/progressive brain metastases, no evidence-based recommendations can be made on this topic.

\section{Key issues for further investigation}

This systematic review of the evidence highlights the critical need for comparative studies that directly evaluate the outcome of different treatment modalities for patients with recurrent/progressive metastatic brain disease, while simultaneously addressing the role of tumor histopathology in treatment outcomes. In addition, understanding potential differences in the mode of death (neurologic versus systemic progression), will help answer the important question of whether treating recurrent/progressive lesions delays neurologic progression long enough to allow more aggressive therapy for the primary systemic disease.

Moreover, specific patient characteristics offer important clinical variables in evaluating treatment for recurrent/ progressive metastases, such as if the recurrence/progression occurs at the site of the primary focal treatment (surgery or SRS) and if it is clinically symptomatic or discovered because of routine surveillance neuroimaging. Indeed, as the treatment of recurrent/progressive brain metastases is undertaken primarily with palliative intent, it is important to stress which symptoms these treatments are poised to address and how overall patient quality of life is going to be affected by any re-treatment modality.

No ongoing or recently closed randomized clinical trials addressing the re-treatment of patients with recurrent/ progressive brain metastases were found that met the eligibility criteria.

Acknowledgments We would like to acknowledge the contributions of the McMaster Evidence-based Practice Center (EPC), Dr. Parminder Raina (Director). Dr. Lina Santaguida (Co-Associate Director, Senior Scientist) led the EPC staff, which was responsible for managing the systematic review process, searching for and retrieving, reviewing, data abstraction of all articles, preparation of the tables and the formatting and editing of the final manuscripts. We would also like to acknowledge the contributions of Roxanne Martinez in preparing this manuscript.

Disclaimer of liability The information in these guidelines reflects the current state of knowledge at the time of completion. The presentations are designed to provide an accurate review of the subject matter covered. These guidelines are disseminated with the understanding that the recommendations by the authors and consultants who have collaborated in their development are not meant to replace the individualized care and treatment advice from a patient's physician(s). If medical advice or assistance is required, the services of a competent physician should be sought. The proposals contained in these guidelines may not be suitable for use in all circumstances. The choice to implement any particular recommendation contained in these guidelines must be made by a managing physician in light of the situation in each particular patient and on the basis of existing resources.

Disclosures All panel members provided full disclosure of conflicts of interest, if any, prior to establishing the recommendations contained within these guidelines.

Open Access This article is distributed under the terms of the Creative Commons Attribution Noncommercial License which permits any noncommercial use, distribution, and reproduction in any medium, provided the original author(s) and source are credited.

\section{References}

1. Patchell RA (2003) The management of brain metastases. Cancer Treat Rev 29(6):533-540

2. Robinson PD, Kalkanis SN, Linskey ME, Santaguida PL (2009) Methodology used to develop the AANS/CNS management of brain metastases evidence-based clinical practice parameter guidelines. J Neurooncol. doi:10.1007/s11060-009-0059-2

3. Centre for Evidence-Based Physiotherapy (2009) Physiotherapy Evidence Database (PEDro). http://www.pedro.org.au/. Last Accessed in Jan 2009

4. Maher CG, Sherrington C, Herbert RD, Moseley AM, Elkins M (2003) Reliability of the PEDro scale for rating quality of randomized controlled trials. Phys Ther 83(8):713-721

5. Cooper JS, Steinfeld AD, Lerch IA (1990) Cerebral metastases: value of reirradiation in selected patients. Radiology 174(3:Pt 1):883-885

6. Sadikov E, Bezjak A, Yi QL, Wells W, Dawson L, Millar BA et al (2007) Value of whole brain re-irradiation for brain metastases-single centre experience. Clin Oncol (R Coll Radiol) 19(7):532-538

7. Wong WW, Schild SE, Sawyer TE, Shaw EG (1996) Analysis of outcome in patients reirradiated for brain metastases. Int J Radiat Oncol Biol Phys 34(3):585-590

8. Arbit E, Wroski M, Burt M, Galicich JH (1995) The treatment of patients with recurrent brain metastases. A retrospective analysis of 109 patients with nonsmall cell lung cancer. Cancer 76(5):765-773

9. Bindal RK, Sawaya R, Leavens ME, Hess KR, Taylor SH (1995) Reoperation for recurrent metastatic brain tumors. J Neurosurg 83(4):600-604

10. Truong MT, St Clair EG, Donahue BR, Rush SC, Miller DC, Formenti SC et al (2006) Results of surgical resection for progression of brain metastases previously treated by gamma knife radiosurgery. Neurosurgery 59(1):86-97

11. Vecil GG, Suki D, Maldaun MV, Lang FF, Sawaya R (2005) Resection of brain metastases previously treated with stereotactic radiosurgery. J Neurosurg 102(2):209-215

12. Akyurek S, Chang EL, Mahajan A, Hassenbusch SJ, Allen PK, Mathews LA et al (2007) Stereotactic radiosurgical treatment of cerebral metastases arising from breast cancer. Am J Clin Oncol 30(3):310-314

13. Chen JC, Petrovich Z, Giannotta SL, Yu C, Apuzzo ML (2000) Radiosurgical salvage therapy for patients presenting with 
recurrence of metastatic disease to the brain. Neurosurgery 46(4):860-866

14. Combs SE, Schulz-Ertner D, Thilmann C, Edler L, Debus J (2004) Treatment of cerebral metastases from breast cancer with stereotactic radiosurgery. Strahlenther Onkol 180(9):590-596

15. Davey P, Schwartz ML, Scora D, Gardner S, O’Brien PF (2007) Fractionated (split dose) radiosurgery in patients with recurrent brain metastases: Implications for survival. $\mathrm{Br} \mathrm{J}$ Neurosurg 21(5):491-495

16. Davey P, O'Brien PF, Schwartz ML, Cooper PW (1994) A phase I/II study of salvage radiosurgery in the treatment of recurrent brain metastases. Br J Neurosurg 8(6):717-723

17. Hoffman R, Sneed PK, McDermott MW, Chang S, Lamborn KR, Park E et al (2001) Radiosurgery for brain metastases from primary lung carcinoma. Cancer J 7(2):121-131

18. Kwon KY, Kong DS, Lee JI, Nam DH, Park K, Kim JH (2007) Outcome of repeated radiosurgery for recurrent metastatic brain tumors. Clin Nerol Neurosurg 109(2):132-137

19. Loeffler JS, Kooy HM, Wen PY, Fine HA, Cheng CW, Mannarino EG et al (1990) The treatment of recurrent brain metastases with stereotactic radiosurgery. J Clin Oncol 8(4):576-582

20. Noel G, Medioni J, Valery CA, Boisserie G, Simon JM, Cornu P et al (2003) Three irradiation treatment options including radiosurgery for brain metastases from primary lung cancer. Lung Cancer 41(3):333-343

21. Noel G, Proudhom MA, Valery CA, Cornu P, Boisserie G, Hasboun D et al (2001) Radiosurgery for re-irradiation of brain metastasis: results in 54 patients. Radiother Oncol 60(1):61-67

22. Sheehan J, Kondziolka D, Flickinger J, Lunsford LD (2005) Radiosurgery for patients with recurrent small cell lung carcinoma metastatic to the brain: outcomes and prognostic factors. J Neurosurg 102(Suppl):247-254

23. Shuto T, Fujino H, Inomori S, Nagano H (2004) Repeated gamma knife radiosurgery for multiple metastatic brain tumours. Acta Neurochir (Wein) 146(9):989-993

24. Yamanaka K, Iwai Y, Yasui T, Nakajima H, Komiyama M, Nishikawa $M$ et al (1999) Gamma Knife radiosurgery for metastatic brain tumor: the usefulness of repeated Gamma Knife radiosurgery for recurrent cases. Stereotact Funct Neurosurg 72(Suppl 1):73-80

25. Abrey LE, Olson JD, Raizer JJ, Mack M, Rodavitch A, Boutros DY et al (2001) A phase II trial of temozolomide for patients with recurrent or progressive brain metastases. J Neurooncol 53(3):259-265

26. Brocker EB, Bohndorf W, Kampgen E, Trcka J, Messer P, Tilgen W et al (1996) Fotemustine given simultaneously with total brain irradiation in multiple brain metastases of malignant melanoma: report on a pilot study. Melanoma Res 6(5):399-401

27. Christodoulou C, Bafaloukos D, Linardou H, Aravantinos G, Bamias A, Carina M et al (2005) Temozolomide (TMZ) combined with cisplatin (CDDP) in patients with brain metastases from solid tumors: a Hellenic Cooperative Oncology Group (HeCOG) Phase II study. J Neurooncol 71(1):61-65

28. Feun LG, Lee YY, Plager C, Papadopoulos N, Savaraj N, Charnsangavej $C$ et al (1990) Intracarotid cisplatin-based chemotherapy in patients with malignant melanoma and central nervous system (CNS) metastases. Am J Clin Oncol 13(5): $448-451$

29. Giorgio CG, Giuffrida D, Pappalardo A, Russo A, Santini D, Salice P et al (2005) Oral temozolomide in heavily pre-treated brain metastases from non-small cell lung cancer: phase II study. Lung Cancer 50(2):247-254

30. Groen HJ, Smit EF, Haaxma-Reiche H, Postmus PE (1993) Carboplatin as second line treatment for recurrent or progressive brain metastases from small cell lung cancer. Eur J Cancer 29A(12):1696-1699

31. Hwu WJ, Lis E, Menell JH, Panageas KS, Lamb LA, Merrell J et al (2005) Temozolomide plus thalidomide in patients with brain metastases from melanoma: a phase II study. Cancer 103(12):2590-2597

32. Iwamoto FM, Omuro AM, Raizer JJ, Nolan CP, Hormigo A, Lassman $\mathrm{AB}$ et al (2008) A phase II trial of vinorelbine and intensive temozolomide for patients with recurrent or progressive brain metastases. J Neurooncol 87(1):85-90

33. Kaba SE, Kyritsis AP, Hess K, Yung WK, Mercier R, Dakhil S et al (1997) TPDC-FuHu chemotherapy for the treatment of recurrent metastatic brain tumors. J Clin Oncol 15(3):1063-1070

34. Omuro AM, Raizer JJ, Demopoulos A, Malkin MG, Abrey LE (2006) Vinorelbine combined with a protracted course of temozolomide for recurrent brain metastases: a phase I trial. J Neurooncol 78(3):277-280 